\title{
Biodegradation of Synthetic Rubbers by a Mixed Culture Isolated from Various Rubber Factory Soils in Songkhla, Thailand
}

\author{
Vilasinee Akkharabunditsakul, Varaporn Tanrattanakul, Kamontam Umsakul
}

\begin{abstract}
Mixed cultures of rubber degrading bacteria were isolated from soils of rubber factories in Songkhla province, Thailand. Mixed culture B could utilize latex as the sole carbon source on agar plate and over 30 days, a maximum of $7.38 \%$ and $7.78 \%$ weight loss was obtained respectively utilizing rubber gloves and polyurethane foam made from natural rubber. The FT-IR results confirmed the reduction that associated with double bonds in cis-1,4polyisoprene, $\mathrm{CH}_{2}$ and $\mathrm{CH}_{3}$ in aliphatic compounds. The formation of aldehyde groups increased as an intermediate during rubber biodegradation. Moreover, the urethane bond in polyurethane foam also was broken down by microbial enzymes. The Mixed culture B was then identified to Gram positive bacterium (B1) and Gram negative bacteria (B2 and B3). All the results in this study have been promising an alternative choice to eliminate the solid waste of rubber synthetic materials.
\end{abstract}

Keywords - Biodegradation, synthetic rubber, mixed culture.

\section{INTRODUCTION}

Natural rubber in latex form is a biopolymer consisting of isoprene units in cis-configuration. The cis-polyisoprene has been found in over 2,000 species of higher plants and fungi [1]. "Hevea brasilliensis" is a typical example of natural rubber producing plants which produce cis-1,4-polyisoprene. Rubber has high elasticity then it was used globally as a raw material for many rubber products such as belts, gaskets, matting, flooring, gloves, rubber bands, erasers, tires, etc [2]. The total rubber world consumption is estimated to be 26.8 million metric tons including 12.3 tons of natural rubber products and 14.5 million tons of synthetic rubber in 2015 . All rubber products have become a huge problem with solid wastes accumulating in the environment causing severe pollution because of improper recycling management. Biodegradation of polymeric materials has been studied and this is proven to be eco-friendly because of its non-toxic end products such as $\mathrm{CO}_{2}, \mathrm{H}_{2} \mathrm{O}$ [3].

Vilasinee Akkharabunditsakul / Kamontam Umsakul (Authors), Prince of Songkla University, Thailand
There are many reports of rubber degradation by various microorganisms e.g. bacteria, fungi and actinomycetes. The carbon atoms in cis-1,4-polyisoprene backbone can be utilized as the sole carbon and energy source for these microorganisms [4], [5].

In the environment, many kinds of microorganisms are associated in the form of consortia. Previous studies have shown that the microbial consortia are able to degrade the polymeric compounds and utilize different intermediates during each step of the degradation process [6], [7]. However, all strains of microorganisms in consortia cannot be cultured on medium. This is a limitation of using consortia as an inoculum for biodegrading solid waste disposals.

Thus, this study aims to isolate a culturable mixed culture to use as an effective inoculum to degrade the rubber materials including rubber gloves and polyurethane foam made from natural rubber.

\section{MATERIALS AND METHODS}

\section{A. Materials}

Soil samples were collected from rubber factories in Songkhla, Thailand. Rubber gloves were purchased from Sri Trang Agro-Industry Public Company Limited, Songkhla, Thailand and polyurethane foam (PU foam) obtained from Department of Materials Science and Technology, Prince of Songkla University, Hatyai, Thailand. Luria-Bertani agar (LB agar), Plate count agar (PCA) was purchased from SigmaAldrich. Mineral salts medium (MSM) containing as followed: $\mathrm{Na}_{2} \mathrm{HPO}_{4} 9 \mathrm{~g} / \mathrm{L}, \mathrm{KH}_{2} \mathrm{PO}_{4} 1.5 \mathrm{~g} / \mathrm{L}, \mathrm{NH}_{4} \mathrm{NO}_{3} 1 \mathrm{~g} / \mathrm{L}, \mathrm{MgSO}_{4}$. $7 \mathrm{H}_{2} \mathrm{O} 0.2 \mathrm{~g} / \mathrm{L}, \mathrm{CaCl}_{2} .2 \mathrm{H}_{2} \mathrm{O} 0.02 \mathrm{~g} / \mathrm{L}, \mathrm{Fe}(\mathrm{III})\left[\mathrm{NH}_{4}\right]$ citrate $0.0012 \mathrm{~g} / \mathrm{L}$ supplemented with natural rubber latex $0.6 \%(\mathrm{v} / \mathrm{v})$ [8].

\section{B. Screening of Rubber Degrading Bacteria}

Twenty five grams of soil sample were incubated in $225 \mathrm{~mL}$ of MSM broth supplemented with $0.6 \%(\mathrm{v} / \mathrm{v})$ natural rubber latex (NRL) at $30{ }^{\circ} \mathrm{C}, 150 \mathrm{rpm}$ for 30 days. $25 \mathrm{~mL}$ of culture broth was then transferred to a new sterile flask containing fresh MSM+NRL, and after shaking incubated for 15 days in the same conditions as described before. After 15 days, the culture was enriched again. Culture broth was then diluted in $0.85 \% \mathrm{NaCl}$ solution and spread on PCA and MSM+NRL plates according to standard method [9]. Different colonies on MSM+NRL plates were picked and re-streaked for single 
colonies, and 3 different colonies were grouped randomly as mixed cultures.

\section{Biodegradation of Rubber Materials by Mixed Cultures}

Each mixed culture containing equal amounts of each isolate was used as an inoculum $(10 \% \mathrm{v} / \mathrm{v})$ in a shake flask containing MSM and $0.1 \%(\mathrm{w} / \mathrm{v})$ polymer samples (rubber glove, PU foam). All tested flasks were incubated at $30{ }^{\circ} \mathrm{C}$, 150 rpm for 30 days.

\section{Weight Loss of Polymer Materials}

After 30 days of incubation, polymer samples were filtrated by Whatman No.1 filter paper. The dry weight of polymers was determined and the percentage weight loss was calculated according to the following equation.

$\%$ weight loss $=\frac{\text { original weight }(\mathrm{g})-\text { remaining weight }(\mathrm{g})}{\text { original weight }(\mathrm{g})} \times 100$

\section{E. Viable Cells Count}

The culture media after incubation with the different polymers were diluted and spread on PCA plates. Numbers of colonies were counted and were recorded as $\mathrm{CFU} / \mathrm{mL}$.

\section{F. Determination of Rubber Degradation by FT-IR Analysis}

The pieces of rubber glove and PU foam in treated and untreated shake flasks after 30 days of incubation with the mixed culture were taken for FT-IR analysis. The sample pieces were washed with distilled water 2-3 times and dried before analysis. The transmittance spectra were detected in the IR range from 4000 to $400 \mathrm{~nm}$ by ATR-FTIR spectrometer, Bruker Tensor 27.

\section{RESULTS AND DISCUSSION}

\section{A. Screening of Rubber Degrading Bacteria and Mixed Cultures}

The soil samples provided 9 isolates of rubber degrading bacteria on MSM+NRL plates. Three different isolates were picked and grouped to use as the mixed cultures A, B and C. The visual observation of polymers in untreated and those treated with those mixed cultures is presented in Fig. 1. For the rubber glove pieces the color surface changes in the treated samples were clearly observed due to microbial pigment production see Fig. 1 (a-c) whereas, PU foam's surface showed only slightly changes see Fig. 1 (e-g) when compared with control pieces Fig. 1 (d and h). The physical changes, for example, color and shape could be explained in term of microbial colonization and degradation. The steps of biodegradation of any polymer usually start with the microbial attachment on the surface. Then, the microorganisms release some involved degrading enzymes and the long polymer chains can be degraded into shorter chains, dimers and monomers. After that, those intermediates are then absorbed into cells and are utilized as carbon and energy sources. The end products from mineralization are $\mathrm{CO}_{2}, \mathrm{H}_{2} \mathrm{O}$ and $\mathrm{CH}_{4}[3]$.

\section{B. Weight Loss of Polymer Measurement}

The results of weight loss after incubation with the mixed cultures for 30 days are shown in TABLE I. The Mixed culture B could effectively reduce the weight of both rubber glove and PU foam revealing about $7.38 \%$ and $7.78 \%$ weight loss, respectively, whereas the Mixed culture A could degrade only rubber glove. Rubber glove treated with the Mixed culture A showed about $17.06 \%$ of weight loss. This culture gave the highest percentage of rubber glove weight loss. In contrast, the Mixed cultures B and C could degrade both of the rubber substrates. In this study, we aim to isolate a group of mixed culture which is able to degrade various types of rubber materials, therefore the Mixed culture B was considered as the most appropriate representative for using in the next experiments. The basic Gram staining indicated that the Mixed culture B contained a Gram positive rod, non-spore forming (isolate B1), a Gram negative rod (isolate B2), and a Gram negative short rod (isolate B3).

TABLE I

THE PERCENTAGES OF WEIGHT LOSS OF RUBBER GLOVE AND PU FOAM AFTER TREATED WITH THREE MIXED CULTURES AT $30^{\circ} \mathrm{C}, 150$ RPM FOR 30 DAYS

\begin{tabular}{|l|l|l|}
\hline \multirow{2}{*}{$\begin{array}{c}\text { Mixed } \\
\text { culture }\end{array}$} & \multicolumn{2}{|c|}{ \% Weight loss of polymer } \\
\cline { 2 - 3 } & Rubber glove & PU foam \\
\hline A & 17.06 & 0.00 \\
\hline B & 7.38 & 7.78 \\
\hline C & 8.29 & 2.02 \\
\hline
\end{tabular}

\section{Viable Cells Count}

The viable cells count is presented in TABLE II. The initial microbial population was $1.5 \times 10^{7} \mathrm{CFU} / \mathrm{mL}$. After 30 days of incubation, the numbers of viable cells of each isolate decreased significantly. These results could be explained in that bacteria were able to attach on the material's surface, so that the available cells in culture broth then decreased. Because for a long period of incubation in a closed system some intermediates during biodegradation were released into the culture broth, this may have caused undesirable conditions for bacterial growth. The cell viability is also dependent on the ability of each isolate to utilize specific materials as a carbon and energy source as seen in all tested PU foam flasks thus the survival of cells was very low. Reference [10] explains about additives addition, chemical structure and how the material surface are all important factors to reducing the effects of biodegradation.

\section{Determination of Structural Changes Using FT-IR} Analysis

FT-IR analysis was used to determine the change of functional groups of polymer structures. The new formation peaks or disappeared peaks were detected. These changes in 


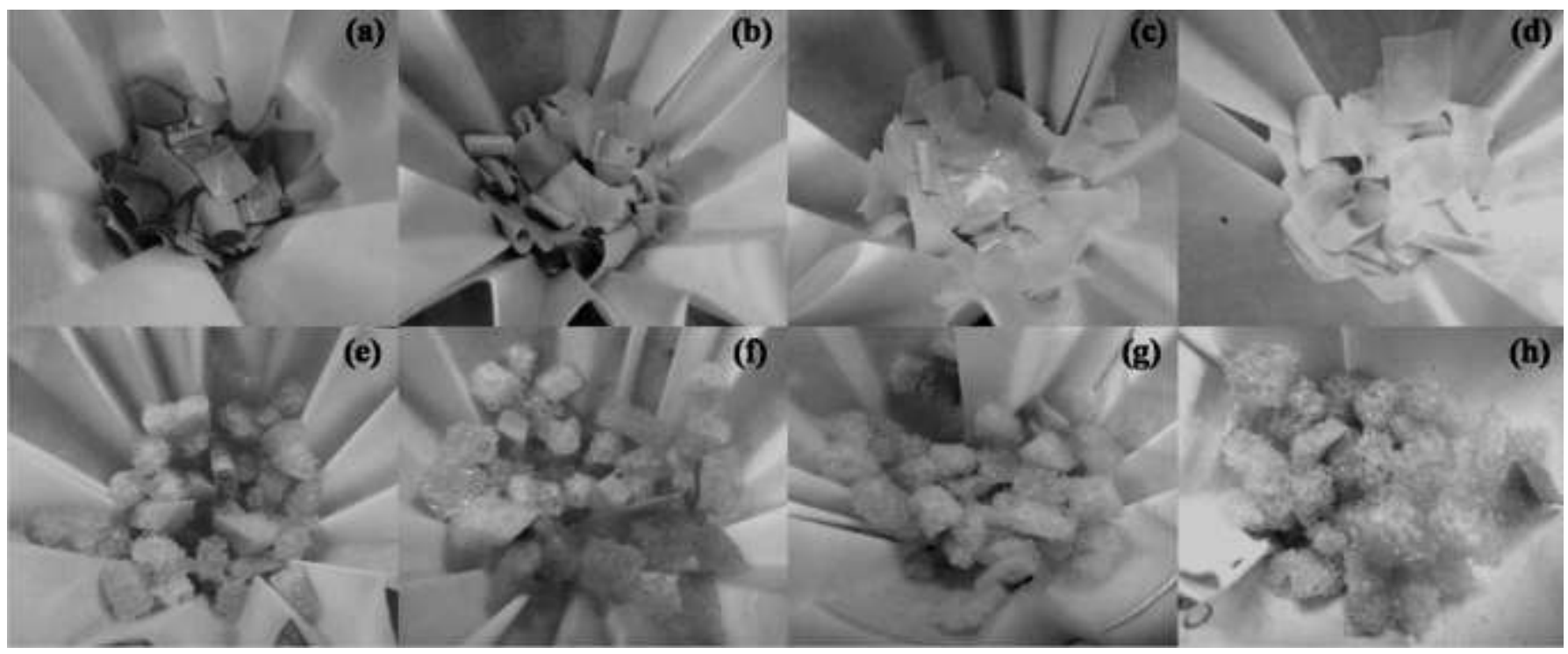

Fig. 1 Visual observation of rubber glove (a-d) and PU foam (e-h) treated with the Mixed culture A (a, e), the Mixed culture B (b, f), Mixed culture $\mathrm{C}(\mathrm{c}, \mathrm{g})$ and abiotic control $(\mathrm{d}, \mathrm{h})$ at $30^{\circ} \mathrm{C}, 150 \mathrm{rpm}$ for 30 days of incubation.

structure are a useful method to confirm the biodegradability of materials. The results of FT-IR spectra showed the changes of rubber glove structure after being incubated with the Mixed culture B in Fig. 2. The wavenumber in the range of 1660 $\mathrm{cm}^{-1}$ indicated the stronger formation of aldehyde groups in treated sample than in the control [11]. This range also overlapped the wavenumbers at 1652 and $1543 \mathrm{~cm}^{-1}$ which were identified as the protein regions with amide I and II according to microbial cell components on material's surface because of microbial attachment [12]. Moreover, the new unidentified peak in the range of $1000-1050 \mathrm{~cm}^{-1}$ was found after treated with the Mixed culture B. A broadening signal of the range at $1300-1500 \mathrm{~cm}^{-1}$ of treated sample was lower than that of the control which was identified as $\delta\left(\mathrm{CH}_{\mathrm{x}}\right)$ deformation vibrations and the decrease of $\mathrm{CH}_{2}$ and $\mathrm{CH}_{3}$ in aliphatic compounds considerably [13]. In addition, a peak at $835 \mathrm{~cm}^{-1}$ referring to double bonds in cis-1,4-polyisoprene has slightly changed. The mechanism involved in the rubber biodegradation may be the oxidative cleavage, which is indicated as the reduction of double bond character and the presence of aldehyde groups and the formation of acids as intermediates [14]. In Gram positive and Gram negative bacteria, they are able to utilize different key enzymes of oxygenases in rubber degradation but can also release similar intermediates during biodegradation containing aldehyde and keto groups [13].

In addition, the degradation of the treated and untreated PU foams was analyzed by FT-IR. In the treated sample, IR spectra mostly overlapped with the IR spectra of control, but at the wavenumber of urethane bond (R-COONH-R'), there was a sight decreased at the wavenumbers 1720 and $1660 \mathrm{~cm}^{-1}$ referring to ester carbonyl group $(\mathrm{C}=\mathrm{O})$ and urethane $(\mathrm{NH})$ in Fig. 3 [15]. The urethane bond in polyurethane foam may be broken down due to the microbial enzymes, whereas the selected microorganisms could not degrade the rubber structure which is used as a raw material in PU foam production. Several previous studies have been reported that the polyurethanases which are a group of hydrolases playing an important role in cleaving the ester or peptide bonds in PU structure [13] but the PU foam may have some limitations about its chemical structure and surface characteristic which may affect the capacity of microorganisms to biodegrade.

TABLE II

NUMBERS OF VIABLE CELLS COUNT OF EACH MIXED CULTURE (CFU/ML) AFTER 30 DAYS OF INCUBATION WITH RUBBER GLOVE AND PU FOAM AT $30^{\circ} \mathrm{C}, 150 \mathrm{RPM}$

\begin{tabular}{|c|c|c|c|}
\hline \multirow{2}{*}{$\begin{array}{c}\text { Mixed } \\
\text { culture }\end{array}$} & \multirow{2}{*}{ Isolates } & \multicolumn{2}{|c|}{ Viable cells $(\mathrm{CFU} / \mathrm{mL})$} \\
\cline { 3 - 4 } & & Rubber Glove & PU foam \\
\hline \multirow{3}{*}{$\mathrm{A}$} & $\mathrm{A} 1$ & $2.6 \times 10^{6}$ & $2.8 \times 10^{4}$ \\
& $\mathrm{~A} 2$ & $1.5 \times 10^{6}$ & $8.0 \times 10^{4}$ \\
& $\mathrm{~A} 3$ & $1.0 \times 10^{4}$ & $1.0 \times 10^{4}$ \\
\hline \multirow{3}{*}{$\mathrm{B}$} & $\mathrm{B} 1$ & $1.7 \times 10^{5}$ & $1.0 \times 10^{5}$ \\
& $\mathrm{~B} 2$ & $2.8 \times 10^{7}$ & $9.0 \times 10^{4}$ \\
& $\mathrm{~B} 3$ & $2.5 \times 10^{8}$ & $1.5 \times 10^{6}$ \\
\hline \multirow{3}{*}{$\mathrm{C}$} & $\mathrm{C} 1$ & $1.0 \times 10^{3}$ & $1.1 \times 10^{2}$ \\
& $\mathrm{C} 2$ & $6.0 \times 10^{8}$ & $2.5 \times 10^{8}$ \\
& $\mathrm{C} 3$ & $1.6 \times 10^{2}$ & $1.0 \times 10^{2}$ \\
\hline
\end{tabular}

\section{CONCLUSIONS}

The objective of this study was to isolate a culturable mixed culture from soils in rubber factories in Songkhla province, Thailand capable of degrading two different kinds of synthetic rubber materials namely rubber gloves and PU foam. Nine selected isolates were grouped as the three mixed cultures and then tested for rubber biodegradability in liquid medium for 30 days. Weight loss was measured to identify the mixed culture which had the capacity to maximize the weight loss of both rubber materials. The Mixed culture B containing isolate B1 (Gram positive rod non-spore forming), B2 (Gram negative rod) and B3 (Gram negative short rod) gave between 7 and $8 \%$ weight loss for both the rubber gloves and the PU foam. 


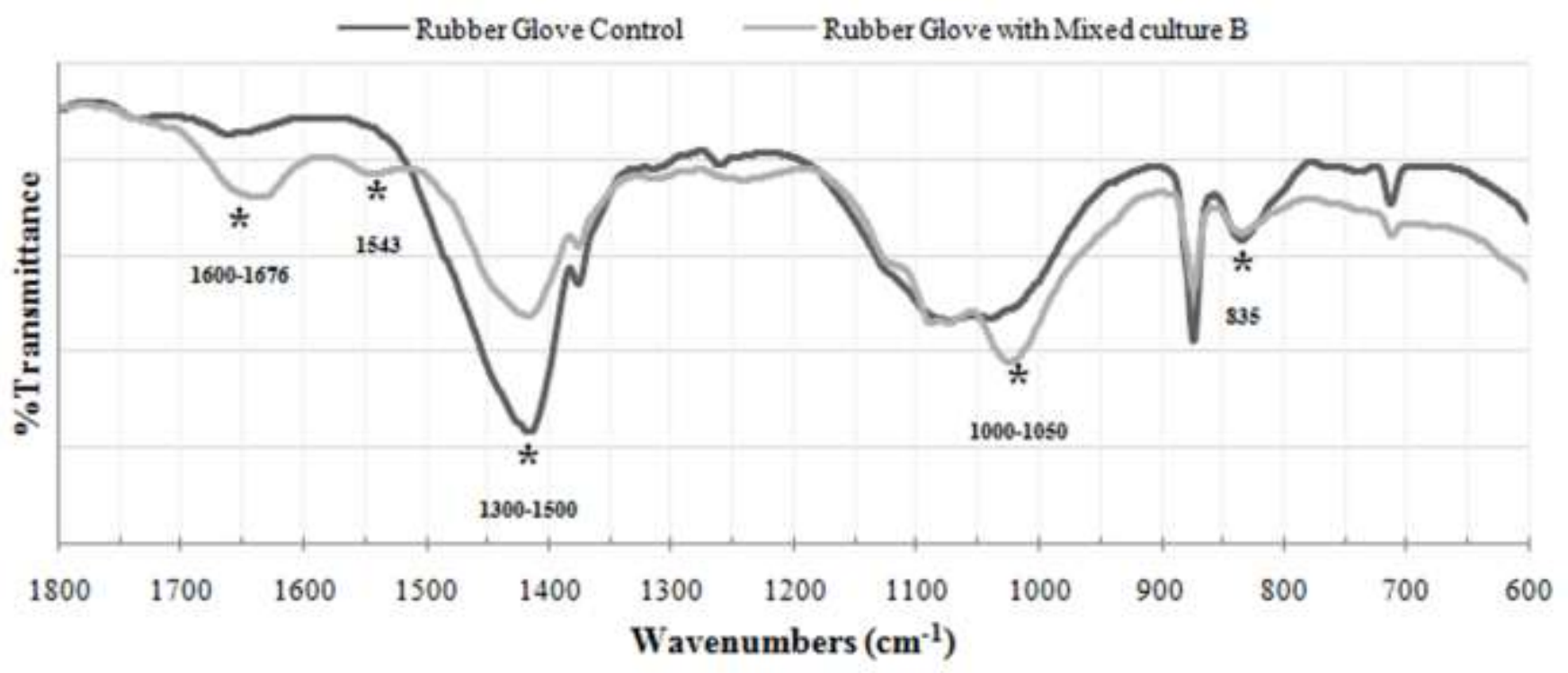

Fig. 2 FT-IR spectra of untreated and treated rubber gloves with the Mixed culture B at $30{ }^{\circ} \mathrm{C}, 150 \mathrm{rpm}$ for 30 days

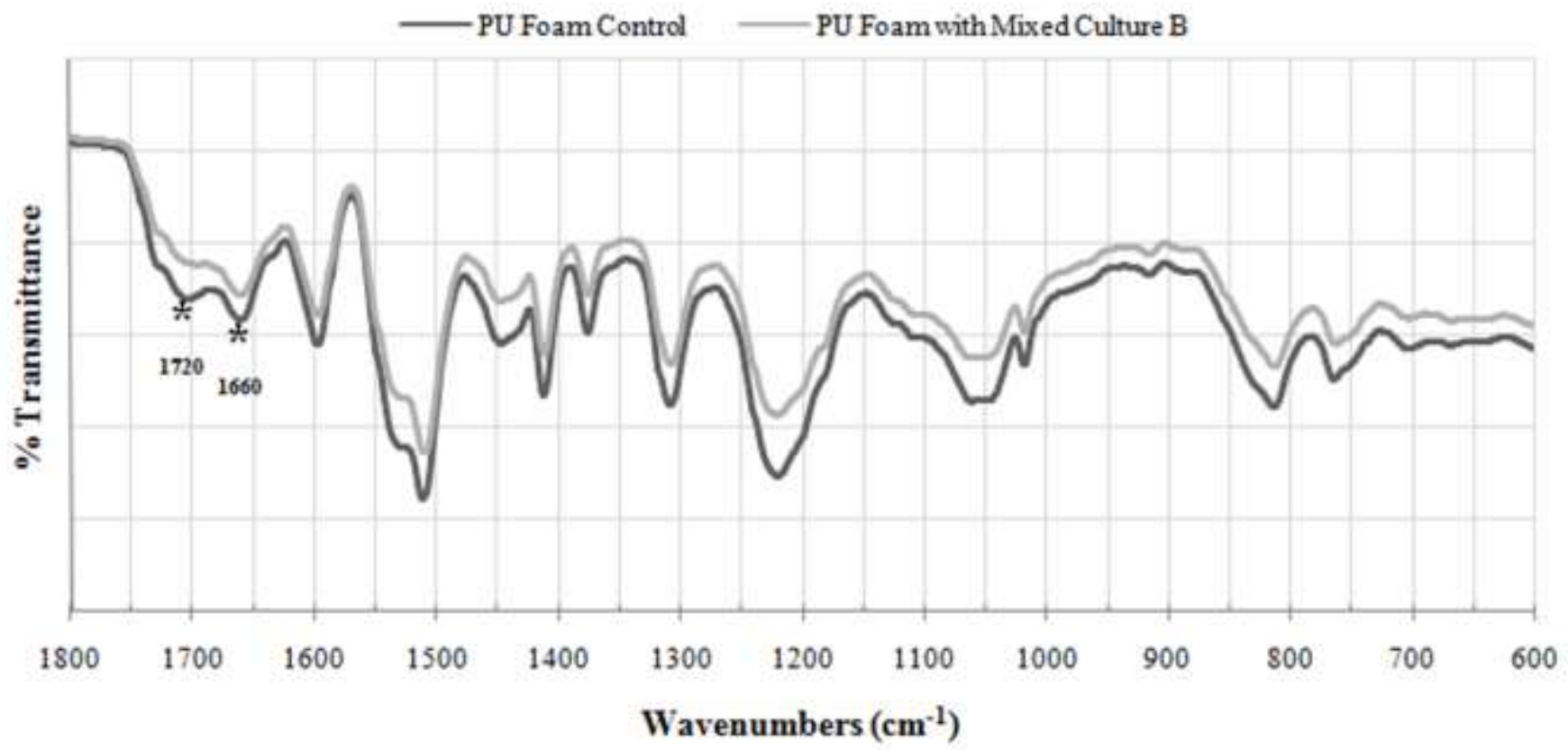

Fig. 3. FT-IR spectra of untreated and treated PU foam with the Mixed culture B at $30{ }^{\circ} \mathrm{C}, 150 \mathrm{rpm}$ for 30 days

FT-IR analysis confirmed that the Mixed culture B was able to degrade both the rubber gloves and the PU foam in 30 days of incubation. These mixed cultures should be studied further for their ability to be utilized with the other rubber waste products.

\section{ACKNOWLEDGMENT}

We would like to gratefully thank the Department of Materials Science and Technology, Prince of Songkla University, Songkhla, Thailand for supplying the PU foam and for advising on FT-IR analysis. The work was financially supported by the Department of Microbiology and graduate school of Prince of Songkla University. Finally regarding the English language version we really appreciate the help and advice of Mr. Christopher Howell.

\section{REFERENCES}

[1] T. Koyama, A. Steinbüchel, "Chemical structure and occurrence of natural polyisoprenes (Book style with paper title and editor)," in Biopolymers, vol. 2, A. Steinbüchel, Ed. Weinheim: WILEY-VCH Verlag GmbH, 2001, pp. 1-25.

[2] B. L. Archer, B. G. Audley, "Rubber, gutta percha and chicle, in: Phytochemistry, vol. 2, F. F. Nord, L. P. Miller, Eds. New York: Van Nostrand Reinhold, 1973, pp. 310-343. 
[3] D. M. Abou-Zeid, R. J. Müller, W. D. Deckwer, "Degradation of natural and synthetic polyester under anaerobic condition," J.Biotechnol., vol. 86, pp. 113-126, Aug. 2000. https://doi.org/10.1016/S0168-1656(00)00406-5

[4] J. Birke, W. Röther, G. Schmitt, and D. Jendrossek, "Functional identification of rubber oxygenase (RoxA) in soil and marine myxobacteria," Appl. Environ. Microbiol., vol. 79, pp. 6391- 6399, Oct. 2013. https://doi.org/10.1128/AEM.02194-13

[5] S. Imai, K. Ichikawa, Y. Muramatsu, D. Kasai, E. Masai, and M. Fukuda, "Isolation and characterization of Streptomyces,

Actinoplanes, and Methylibium strains that are involved in degradation of natural rubber and synthetic poly(cis-1,4-isoprene)," Enzyme Microb. Technol., vol. 49, pp. 526-531, May. 2011.

[6] S. Skariyachan, M. Megha, M. N. Kini, K. M. Mukund, A. Rizvi, and K. Vasist, "Selection and screening of microbial consortia for efficient and ecofriendly degradation of plastic garbage collected from urban and rural areas of Bangalore, India," Environ. Monit. Assess., vol. 187, pp. 1-14, Jan. 2015. https://doi.org/10.1007/s10661-014-4174-y

[7] A.A. Shah, F. Hasan, J. I. Akhter, A. Hameed, S. Ahmed, "Degradation of polyurethane by novel bacterium isolated from soil," Ann. Microbiol., vol. 58, pp. 381-386, Jun. 2008. https://doi.org/10.1007/BF03175532

[8] D. Jendrossek, G. Tomasi, and R. M. Kroppenstedt, "Bacterial degradation of natural rubber: a privilege of actinomycetes?," FEMS Microbiol. Lett., vol. 150, pp. 179-188, Feb. 1997. https://doi.org/10.1016/S0378-1097(97)00072-4

[9] P. Li, G. Ji-Guang, Y. Bo, and C. Shu-Pei, "Contribution to deterioration of polymeric materials by a slow- growing bacterium Nocardia corynebacterioides," Int. Biodeterior. Biodegr., vol. 63, pp. 24-29. Jul. 2009. https://doi.org/10.1016/j.ibiod.2008.06.003

[10] G. T. Howard., "Biodegradation of polyurethane: a review," Int. Biodeter. Biodegr., vol. 49, pp. 245-252, Jun. 2002. https://doi.org/10.1016/S0964-8305(02)00051-3

[11] S. N. S. Hapuarachchi, S. R. Kariyapper, M. B. D. M. D. Gunawardana, S. Egodage, and T. U. Ariyadasa, "Biodegradation of natural rubber latex by a novel bacterial species isolated from soil," in Conf. Rec. 2016 IEEE MERCon., $\quad$ pp. 1-4. https://doi.org/10.1109/mercon.2016.7480156

[12] A. Linos, M. M. Berekaa, R. Reichelt, U. Keller, J. Schmitt, H. Flemming, R. M. Kroppenstedt, and A. Steinbüchel, "Biodegradation of cis-1,4-polyisoprene rubbers by distinct actinomycetes: microbial strategies and detailedsurface analysis," Appl. Environ. Microbiol., vol. 66, no. 4, pp. 1639-1645, Apr. 2000. https://doi.org/10.1128/AEM.66.4.1639-1645.2000

[13] A. A. Shah, F. Hasan, Z. Shah, N. Kanwal, and S. Zeb., "Biodegradation of natural and synthetic rubbers: A review." Int. Biodeter. Biodegr., vol. 83, pp. 145-157, Jun. 2013. https://doi.org/10.1016/j.ibiod.2013.05.004

[14] E. Cherian, and K. Jayachandran., "Microbial degradation of natural rubber latex by a novel species of Bacillus sp. SBS ${ }^{25}$ isolated from soil.” Int. J. Environ. Res., vol. 3, no. 4, pp. 599-604, Apr. 2009.

[15] M. Urgun-Demirtas, D. Singh, and K. Pagilla., "Laboratory investigation of biodegradability of a polyurethane foam under anaerobic conditions." Polym. Degrad. Stabil. vol. 92, pp. 1599-1610, May, 2007.

https://doi.org/10.1016/j.polymdegradstab.2007.04.013

About Author (s):

Isolation of a culturable mixed culture
from soils is an alternative method and a
step closer to achieving the complete
synthetic rubber biodegradation.

